\title{
Everyday Life and Wellbeing among the Oldest Elderly in Norway-A Qualitative Study
}

\author{
Arild Granerud*, Irene Imingen, Bengt Eriksson \\ Inland Norway University of Applied Sciences, Elverum, Norway \\ Email: *Arild.granerud@inn.no
}

How to cite this paper: Granerud, A. Imingen, I. and Eriksson, B. (2017) Everyday Life and Wellbeing among the Oldest Elderly in Norway-A Qualitative Study. Open Journal of Social Sciences, 5, 97-111. https://doi.org/10.4236/jss.2017.57007

Received: May 20, 2017

Accepted: July 9, 2017

Published: July 12, 2017

Copyright $\odot 2017$ by authors and Scientific Research Publishing Inc. This work is licensed under the Creative Commons Attribution International License (CC BY 4.0).

http://creativecommons.org/licenses/by/4.0/

\section{cc) (i) Open Access}

\begin{abstract}
Background: Demographic changes in the European countries are resulting in an increase in the proportion of elderly. The life conditions and mental health of older people are fields with insufficient knowledge. Demographical changes, socioeconomic factors, as well as urban-rural dimensions affect their situation and demand multifactorial developmental approaches. This is also in line with the emerging gerontological theory of gerotranscendence. There has been a tendency to see the elderly as a homogeneous group, an idea that is challenged by recent research on the "third" and "fourth" age. The everyday life and health of older people-particularly in relation to their mental health - are thus affected by many different circumstances and developments in society, which also interact with each other in complex patterns. Objectives: To develop a deeper understanding of how older people experience, regard and describe their life situation and mental health in urban and rural areas. Method: A descriptive and exploratory qualitative study, where elderly older than 80 in rural and urban areas in Norway were interviewed. In total, 23 interviews were completed ( 7 men, 16 women, 83 to 94 years old). The data were analyzed by means of a qualitative content analysis. Results: The analysis shows some differences between the two geographical areas, and gerotranscendence can be recognized. The main findings are analyzed as six themes: Satisfaction and enjoying life as a basic mood, An organized everyday life, built on activities. To manage on your own is of utmost importance. Strategies to handle hardships and challenges, an indispensable social network, and trust in the welfare state, however sometimes are conditioned. Conclusions: People in the "fourth age", interviewed in this study have developed strategies to handle their everyday life and experience wellbeing. The empirical findings seem to be well in line with the theory of gerotranscendence. Urban-rural differences are found to be limited and related to the individual's life stories.
\end{abstract}

\section{Keywords}

Everyday Life, Oldest Elderly, Qualitative Method 


\section{Introduction}

It is a well-known fact that the European population is growing older [1]. Next to Japan, Europe has the oldest population, and the average length of life within the European Union (EU) is almost 80 years [1]. In Norway, closely connected to the EU, the average life span is 84 for women and 80 for men [2]. However, life span varies greatly across the countries of Europe. A general trend is that the average length of life increases, and the difference between men and women tends to decrease. A study from a number of western European countries predicts that half of the children born after the turn of the millennium will reach 100 years of age [3]. It is important to emphasize that this is "a story of success", that most people can look forward to living an entire life, experiencing childhood, adolescence, adulthood, middle age and old age.

The increasing average life span has given rise to the concepts of "the third age" and "the fourth age" [4]. The third age is the period when working life has passed, but before health problems and the need for formal or informal support have put substantial limitations on everyday life. The third age can, therefore, be characterized by a high degree of freedom and self-realization, but also has the potential for informal help and support to grown-up children, grandchildren, partners and society. The fourth age, around 80 years and above, more often comes with health deficiencies and losses, causing a greater need for medical aid and social care [5]. At the same time, this is the section of the population that grows the fastest [1]. Therefore, it seems to be important to increase the knowledge of everyday life and health for people in the fourth age.

\subsection{Mental Health and Old Age}

Senior citizens often define health based on the ability to be active and participate in social contexts [6]. Participation in or performance of various activities provides a sense of independence [7]. For many older people with disabilities there are fewer opportunities to fill their days with meaningful activities, which can lead to a feeling of emptiness and a sense of a monotonous life [8]. Relationships with other people are perceived as the mainstay of good mental health [9]. Through verification of themselves and their value in relation to others, mental health improves [10]. Mental health changes can be a greater loss than physical changes [11]. Sensory loss, such as reduced vision and hearing, leads many senior citizens to participate less in social interactions, and therefore contributes to a sense of loneliness [12].

Even though mental health problems occur in all ages, there is an increasing risk to be affected, connected to higher age. A study from England and Wales showed that the occurrence of suffering from depression in older people living at home was 9.7\% [13]. Depression seldom occurs alone, the condition is often seen alongside anxiety, cognitive impairment and dementia. Depression is often present among persons over 75, while anxiety often occurs in those under 75 [13] [14].

However, it is not ageing itself that causes deteriorated mental health, and it is 
important to underline that most people in older age have a positive view of life [15]. Regardless, the ongoing demographic changes necessitate increased focus on health and social care services for old people, with the aim to prevent and cure ill health and maintain good health.

\subsection{Different Perspectives on Aging}

There are several theories that try to explain the psychosocial ageing process. Probably the most widely used in research is Erikson's theory [16] [17]. It has had a major impact on the view of old age as the last stage of psychosocial development. Erikson's theory suggests a positive view of old age. He describes the development of human beings in terms of evolution in eight-later extended to nine-stages, of which the last stage is old age and the psychological challenges faced by people in the transition to this phase. According to his theory, to avoid a psychosocial crisis it is essential to know how to resolve this phase. At this stage a meaningful whole can be created within the context of a person's entire life. To accept the life that is lived, with its events and experiences, can lead to the development of wisdom, which, according to Erikson, is closely related to acceptance of meeting death [16] [17].

A theory of ageing that has gained increasing attention is that of gerotranscendence. Tornstam [18] [19] claims that gerotranscendence is the final stage in a natural process towards maturation and wisdom. It represents a shift in metaperspective, from a materialistic and rational view of the world, to a more cosmic and transcendent view [20]. The development of gerotranscendence affects different dimensions. Changes in the cosmic dimension relate to an increasing sense of connection to earlier generations, a new understanding of life and death, and acceptance of the mystery dimension of life. Self-confrontation, decrease of self-centredness, increased self-awareness and ego integrity are associated with the dimension of self. In old age the individual with a transcendent perspective experiences a need to spend more time on meditation and less on material things and superficial social relationships [18] [19]. Tornstam labels this form of activity transcendence and says that it helps to enhance the experience of a good life [20].

\subsection{Factors Concerning Older People's Quality of Life}

Well-being is a concept with different interpretations. Here we rest on the subjective position, meaning that people's lived experiences and evaluations are the basis for well-being (and, of course, lack of well-being) [21]. This subjective perspective, in its present form, comprises, among others, so called hedonic theories, where well-being is understood as a feeling of pleasure and satisfaction, and a non-existence of discomfort [22]. Theories focusing on life satisfaction assume that well-being comes from an informed evaluation of, or attitude to, circumstances in life [23]: To what extent does the individual feel satisfied and content with person's life and life circumstances? Basically, it is the person's own experience or understanding that decides whether well-being is present or not [24]. 
Recent research on quality of life and longevity has revealed new and interesting perspectives. In a number of identified areas or regions around the world -labelled as "blue zones"-people seem to reach a distinctive higher age than average [25]. There are a number of factors common to these areas: People eat healthy and varied food, they continue to be active even in very high agehowever, adjusted to the individual's capacity, they experience a sense of meaningfulness, and last but not least, they belong to a social context, assuring social support and exchange with others [25]. These findings are well in line with Antonovskys [26] theory of Sense of coherence (SOC), where comprehensibility, manageability and meaningfulness are the three elements that together constitute Sense of coherence. Antonovsky [26] found that people who experienced these qualities, even though they lived under severe strain, could survive and develop a good quality of life [27].

The aim of this study is to develop a deeper understanding of how older people experience, regard and describe their life situation and mental health in urban and rural life environments. The point of departure, in accordance with the life-course perspective (ref), is that people's conception of their present situation mirrors their individual biography, as well as factors connected to the local community.

\section{Method}

This is a descriptive and exploratory qualitative study [28] where people above 80 years of age, in rural and urban areas in Norway, were interviewed. These geographical areas were chosen to enable fruitful comparisons from different socio-economical and health-related aspects. The semi-structured qualitative interviews [29] were analyzed using a hermeneutical-phenomenological method [28] [30] [31].

The municipalities Tolga and Os in Nord-Østerdal in east-central Norway, and the district Sagene in Oslo, were invited and accepted to participate. Managers in health and social services were asked to distribute a letter of introduction to potential interview subjects. Inclusion criteria were that the informants should be over 80 years old, live in an independent house or apartment and have competence to give consent. Exclusion criteria were that the informants suffered from dementia or stayed in a nursing home or hospital. The sample might be characterized as theoretical and criterion-guided, however with no claim of statistical representativeness.

Tolga and Os are municipalities in a rural, vast and sparsely populated part of Norway, with around 2000 inhabitants each, of which approximately $6 \%$ are over 80 years of age. Primary industries are the main workplace. Sagene is part of Oslo, with around 39.000 residents, of which $2 \%$ are over 80 years old. The district is fairly close to the center, and has a stable population with many elderlies.

The life-world of the persons interviewed [32], i.e. their daily life and present life situation, but also their entire life-course, were central topics in the interviews [29]. Issues on social network, mood and mental health (present and pre- 
vious), physical problems and the limitations they may bring, and the opinion of help and support received, were treated in the interviews, which ended with the open question: "What is most important in your life as it is right now?" The interviews took place in the homes of the informants, according to their wishes, and lasted about one hour.

In total, 23 interviews were completed. In Sagene, nine women and one man, aged 83 to 94, were interviewed. In Tolga and Os, seven interviews with women and six with men, altogether 13 interviews, ranging in age from 80 to 97 , were conducted.

The data was analyzed by means of a qualitative content analysis [33], adopting the following stages, inspired by Graneheim and Lundman [31]: 1) After being transcribed verbatim, all interviews were repeatedly read through. 2) Codes and analytical traces were identified. 3) Overarching themes were subsequently identified and labelled. 4) The content within each theme was made clear and again validated against the raw data. Significant statements were identified and contributed to this validation; some of them are used as quotations in the result presentation. All three authors were conducting an initial, separate analysis through reading the entire empirical data and formulating preliminary categories. The results were compared and found to be mainly corresponding, however with different formulations.

\section{Ethical Considerations}

Older people can be in a vulnerable situation, because they may be dependent on help from others. Vulnerability and competence to consent were specifically assessed for each participant through a conversation especially to assess whether participants were in satisfactory mental state before the actual interview and throughout the interview situation of the interviewer. Participation was voluntary and based on oral and written information about the study before signing a written consent form. The information comprised that participation was voluntary and that they could withdraw consent at any time without any consequences, that all data were to be kept confidential and stored in a de-identified form, and that no names or other information enabling identification were to be used in the report. The study's research ethics were evaluated by the Data Protection Officer (Norwegian Social Science Data Services), and approved in decision 2025/13/05. The Declaration of Helsinki guidelines were taken into account [34].

\section{Results}

The analysis ended in six overarching themes, reflecting the entire content of the interviews. They differ in range but are situated on the same analytical level. See Table 1 for overview of the themes.

\subsection{Characteristics of the Interviewed Persons}

In Tolga and Os most of these interviewees lived in their own houses, in some cases close to relatives. The areas were rural, with few houses in the neighbour- 
Table 1. Overarching themes from qualitative analysis of interviews with old people in three Norwegian municipalities/part of municipalities.

Themes:

- Satisfaction and enjoying life as a basic mood

- An organized everyday life, built on activities

- To manage on your own is of utmost importance

- Strategies to handle hardships and challenges

- An indispensable social network

- Trust in the welfare state, however sometimes conditioned

hoods, and often long distances to shops and service institutions, up to $30 \mathrm{~km}$. Some stayed in the apartments or houses in the municipal centre, and in some cases in sheltered housing. In Sagene, they all lived urban in separate apartments, but almost half lived in a senior house owned by the National Association of Public Health in Oslo, where they could buy dinner and participate in joint activities. Almost everyone had family, but not necessarily nearby, and none of the interviewees (except one) had a spouse anymore. None of the interviewees had academic education or had had such work. Most had worked within the primary industry or as "blue collar workers". Everyone had some kind of health challenges, of varying strength. Most of the interviewees had challenges in getting out for errands outside their house.

\subsection{The Overarching Themes Described, Developed and Deepened by Quotations}

\subsubsection{Satisfaction and Enjoying Life as a Basic Mood}

When one has reached the age of the persons interviewed, life has comprised a great range of experiences and changes. Common to almost all is a fundamentally positive view of life as something basically good, at least in a longer perspective; "even in hard times [I have] been convinced that there will come a sunrise again..." (man, 87 ).

When one looks back on life, it has not always been simple and positive. Rather the opposite, it has often brought strains, for instance in working life, with hard work, disease and bad conditions. However "a life without hardship is maybe not quite healthy either ..." (woman, 90). Many have earned their living by hard work on small farms-especially interviewees from the rural part of the study, others by heavy industrial work or at sea, while some have worked in shops or at home, taking care of children and family. When there was no work to find, one might, as some describe it, be forced to apply for subsidies;

"... and then mum and dad got 10 crowns per week to live for, 4 for each grown up and 2 for me, it is dreadful to think of ... it was quite a shame you know... now we live like cows in a green meadow .... both workers and pensioners" (woman, 90).

For all of the interviewed life has meant losses and separations from family members and relatives, through diseases or death. More or less all have been 
married, but now live alone. Other sorts of losses might be for example that one party of a couple has to live in a nursing home during the last years of life. However, losses do not only concern spouses, unexpectedly often one has lost children and even grandchildren (through accidents or diseases). Other and more prosaic losses might concern difficulties to keep up with the fast development when it comes to for instance communication technology.

"... I have been very strong but, it is strange, when you get older you feel a bit more dependent on help, and loneliness and then it can be hard ..." (woman, 97).

Few of our informants had learnt how to handle a computer, but those who had, used it for example for contact via skype with grandchildren living far away. Mobile phones, on the other hand, were frequently used. For those living in rural areas, the amount of spontaneous contact has diminished; it is not as common to visit neighbours as it used to be. In the larger city, and especially for those living in a senior centre, the possibilities for contact with others is much better, and highly appreciated by many. While others are more sceptical to close contact. Memories from World War II and the occupation of Norway are recognised by some. The war had consequences in many ways, emotionally and concrete. Experiences of military presence and war are among those consequences, but also the result of having been seen as too kind to the occupant power. These experiences from the years of war seem to have affected our interviewees deeply.

Despite all the challenges and trials life has meant, a common pattern among our interviewees is a basic mood of joy and zest for life. Most of them have carried this positive attitude through life, and they are content with their life when looking back, even though there are things they would have liked to handle differently. Even if and when the physical health will deteriorate, they will keep this joy of life, this feeling of being alive.

The best everyday life now is a day when you are healthy, can move around, do your cooking and take a rest when you want to.

"I have found out that I will not think too much. If you are reasonably healthy and can stand on your feet, then the time can just pass by. Because you can't do anything about it. Just take the best" (woman, 91).

However, there are existential thoughts about life and how it will end as well. Several informants are content with the length of their life, and do not wish to live that much longer. Some are even more prepared to end their 'earthly life'. But still they enjoy the life they have. Many look back on life the way it has developed. One has lived a long life and is by and large content with it, but at the same time conscious of how it can end any day. It seems that this 'border position' has not changed the fundamental view of life. One man said that he has had "a very happy life", one woman said "I have had a very good spirit". Even though the life course did not develop as one had thought, one has "had a good time". An individually based Christian belief, and expectation of a future life in another form, for some give rise to a special tranquillity:

"... for me it is as natural as this-I go to bed in the evening and get to sleep, 
if I wake up in one hundred years or in one hour, it is exactly the same, it is not frightening at all ..." (man, 87).

Others experience this long perspective by keeping in contact with succeeding generations: “. .. and I am very delighted for these children, and do want to keep in contact all the time. Because, as I say, when I am gone, I want them to know who their great grandmother was, and this will not happen unless I all the time keep on expressing that I now want to see him, or that now I want to see her..." (woman, 94).

\subsubsection{An Organized Everyday Life, Built on Activities}

Most of the interviewees tell about a rather organized everyday life, containing a great deal. The daily routines are generally the same every day. The daily activities (i.e. the morning routine) takes longer than before, but can be performed in a lowered tempo and with frequent pauses. It is common that one has planned for the daily activities, often social activities together with other elderly people.

"I think I live a very good life, but $P \mathrm{~m}$ a very positive person. I go to the cinema with female friends, visit theatres, sing in a choir for other elderly. These are things that I like" (woman, 83).

Most of the interviewees, except those who live in senior houses, need help and support with transportation by taxi or private transport to get to activities. This is a huge challenge, especially for those living in rural areas, often stopping them in living as active a life as they want.

"The problem is communication, as it often is here in the countryside. Here the bus comes once a week! On Friday at ten past ten I $m$ there. I like to go to the city centre for theatre or a concert, but it is not easy to get there" (woman, 90).

In some cases, one helps others, for instance neighbours and friends for instance needing help to get out. This might be in organised form, like in a pensioner's organisation, or spontaneous, from person to person. Daily activities might be cooking, cleaning house, but also walking following a special schedule, to keep fit. The interviewees tell in most cases with pride and a sense of security about their everyday life, conveying an impression that it gives them meaning and context. "I bring food to those who cannot get out by themselves. It is voluntary, three times a week" (woman, 94).

There are also examples of those who experience their day as burdensome, often connected to bad health. Those who live in urban areas use the possibilities for activities to a larger extent. This comprises cultural activities, meetings in associations, producing things to sell or giving help to others. These activities are related to well-being. Many regard physical activities as important, for instance walking tours for exercise or for shopping. In some cases it can be a question of exercise in a more concrete meaning:

"Then I stand behind a chair and try to sit down as deep as possible, and then get up again quickly .... 5 times, and when you think it works you do it ten times. And now you begin to tell backwards, 10, 9, 8 because then you feel that you have not that much left, and now even less, so it is easier" (woman, 97).

To be active and perform is rewarding (for instance to contribute to voluntary 
work in organized form, or help a spouse). Closeness both to shops and other offers, as well as living in a senior house, enables people to keep their lifestyle longer in urban areas.

\subsubsection{To manage on Your Own is of Utmost Importance}

The informants are all of fairly high age. What do they find most important in life as it is now? On this they mostly agree: To manage on one's own, for as long as possible, and to the extent possible- "I cook for myself" (woman, 97). To do their own shopping is important to the informants. They do have some help in their homes, for instance help showering once a week, food distribution from the nursing home or dosing medicines (pill dispenser). Or a few hours help cleaning the apartment. What they all have in common is that the aid from the municipality is a supplement to what they do themselves, not a replacement. Children and grandchildren who live nearby often contribute so that it is easier, both practically and emotionally, to continue living at home. There is also the informant that moved to a senior citizens' apartment/home for the elderly, had dinner served, but changed after a month or so, and now cooks for him-/herself in his/her own apartment. The background is that they are used to manage on their own and to work hard- "yes, I was strong, I was strong and you know that I was so caught up in work, and for me it was honourable to work" (woman, 97).

Then you have to be healthy, physically, but also "... have something left in your head until the end" (woman, 97). Keeping in motion is important to be able to manage on one's own for as long as possible, sometimes through an exercise programme, as illustrated above. The informants are usually the eldest in their family, and sometimes their homes are somewhat of a hub for children, grandchildren, great grandchildren and other relatives.

Especially for those who live in rural areas, there are problems regarding transportation-both for the elderly to travel to others, but also to receive visits from family and friends.

\subsubsection{Strategies to Handle Hardships and Challenges}

A long life comprises/is made up of experiences of different sorts. Most have had a hard working life-farming, working in the industry or in small businesses. Either you are born in a rural area and have lived there most of your life, or you have moved there at a young age or when you retired. For most, life has meant marriage and children, but none of the interviewees now live with their spousethey are either dead or in a nursing home. How have they handled loss, grief and hardship? Part of the explanation seems to lie in previously described conditions -a positive view on life and a basic tone of joy, sometimes also a trust based in religion. Add to that a realistic and down to earth view of themselves: " $I$ am mentally strong, but I have feelings, but I am so stubborn too. I have my faith, and I am strong in it." (woman, 97).

The informants say they have had periods of dejection and other mental troubles, for some also a stay in the hospital for some time. What they have in common, is that after a while they have moved on, gotten back their positive atti- 
tude-at least with an additional experience. Grief and hardship has taken its time, but has not gotten the better of him or her. This seems to be an implicit strategy, connected to their personality. For some, a Christian belief is a good support to handle hardship and loss.

\subsubsection{An Indispensable Social Network}

Regular contact with family and others, especially neighbours, is a prerequisite for a good old age. Those who feel important to family or other close ones seem most content with life. Help with practical tasks, but mostly feeling wanted, especially by family, is important.

"I am a housewife, and must keep the house in order, and I cook for four. I do feel that when I have taken care of the food and what else is necessary during the day, then that's it. Yes, that's how it is, but I am lucky, not everybody is as healthy (as I am) and can keep it going for so long" (woman, 89).

Some of those interviewed talk of much less contact with other people during the day than they used to have. Especially in rural areas, the village has changed; farms have been closed down and turned into holiday homes instead. The people you meet or spend time with are often from a younger generation. Nearly all had lost their life partner, and there are very few left from their own generation or original social network.

"We spend time with those who live nearby, but you know, there is a difference in age. When you' re above 90, those above 70 are a different generation" (woman, 91). "It's the people that matter, but they all disappear" (man, 85).

Many have children (who in some instances also have retired) that they see often and receive good support from. It is their own children who have become the most important people in life. It is also they who take care of most practical things that they can't do themselves anymore. Contact with grandchildren, and for some also great grandchildren, is an important network factor. That contact is mainly maintained by mobile phone.

Several interviewees say they do not want as much contact anymore, at least not that others come visit them in their apartment, as a number of those living in urban areas expressed it.

Those in the same age they now meet are through associations or meeting points for people their own age, while others who live in welfare service centres for the elderly seem to have a richer social life where they can regulate contact.

"It's very sad-quality of life is important when you grow old, and it means a reduced quality of life not to have access to transportation so you can get around" (woman, 90).

For most, a mobile phone is essential to keep in touch, and it reduces loneliness and gives a feeling of being closer. Still, most important is the personal contact and time together. Those who live with others in senior houses have more points of contact that both give meaning and the contact they want. Still, they miss their family very much. "We meet for coffee at five on Wednesday. It's quite nice, (we) chat and enjoy ourselves" (woman, 85). 


\subsubsection{Trust in the Welfare State, However Sometimes Conditioned}

In spite of a fairly high age, the informants do not receive much help from society, and they do not want it either. Typically, they have some practical help in the house, like floor cleaning, about an hour every or every other week. Some have a safety alarm, but apart from that, not much modern technology was used. Many receive help with medicines and have dinner delivered. They value the care they receive, but they can also be critical of the quality of the services. At the same time, they are aware that times may come where there is an increased need of help in the home, of care, maybe also a room in home for the elderly. Society's policy, that you should live at home for as long as possible, may also be considered and reconsidered: "Many say that it's best to be home. Yes, of course it's best to be home, but when you might not be able to get to the bathroom, and you don't have anyone to help you get there, it's not that good to be home alone, so I ve always said that if I get so ill that I can't manage, then I want to go to the nursing home" (woman, 90).

If they should need more help, they are very confident the resources will be there, that they receive the help they want and need. Some express a hint of reservation-it is good now, but what will happen with new politicians in the municipality/local politicians, or a new doctor at the nursing home? There are also those who think they need more help already, but who hold back and do not want to be a bother. "But it is saddening too, in a way, when one can't live where one wants to..." (woman, 89).

"I am starting to feel more unsafe, especially about walking, so I want a support person, one who comes with me when I go out..." (woman, 89)

\section{Discussion}

The positive attitude was striking. Some informants were lonely, in a slightly depressed emotional state and wanted a different life, but most informants had a generally positive view on life. Could this positive view have contributed to reaching such a high age? It was noticeable that no one had higher education. This might be because the possibilities for education were few during and after World War II, when the informants were the right age for higher education. It could also be because the interviewees live in rural or working class areas. Several had had independent jobs and their own businesses, but formal education was not a topic. The three components in Sense of Coherence [33] is in line with our empiric material: Comprehensibility, manageability and meaningfulness come through differently in different topics. An immediate and non-problematizing attitude to everyday life as it is now and as it has been expressed the intelligibility of life. The ability to handle life and the life story is pointed to in several topics: An organised day with something to do is an expression of the manageability of life, but then the attitude is that most important is to manage on one's own, as expressed by our informants. To have strategies for handling hardship and challenges also means readiness to handle unplanned and unexpected situations. Meaningfulness, which is the motivating, energising component, might lie 
at the front of the first topic-a joy over life, but of course also in the value of a social network. The term Sense of coherence [26] seem to describe the attitude to life described by the informants, they seem to have in common a high degree of Sense of coherence.

Gerontological theories with a life-course perspective have in common that age is viewed in the light of life as a whole, and the supposition that life as an elderly to a high degree/extent is determined by how life as a youth and middle-aged has been [35]. This study is too limited to support general claims of the empirical relevance of a strict life-course perspective. Still, we can see from the life stories the informants tell that they contain many elements that likely have contributed to their relatively good current situation, such as an ability to adapt to changed circumstances and a positive attitude to take on tasks, often physically demanding and long-lasting. Circumstances that may have shaped a realistic and modest view on life, but also a form of agent perspective, an understanding of how life conditions to a certain degree can be swayed and steered. Similarly, Eriksson's [17] description of human/a person's development in nine stages can be seen as a life course theory. A good life in the ninth and last stageold age-means accepting life as it was, and coming to terms/reconciling with not everything being as one would have wanted. Such an attitude leads to wisdom and acceptance before dying. Our informants approach questions about this last stage in life differently. Accepting life as it was/became seems to be a common notion, but not entirely without reservations. Some events in life might still seem meaningless and incomprehensible, like losing a life partner much too soon. Those with an expressed Christian faith seem to a considerable extent to have come to a position of acceptance, but this is also true for informants who see their place in a chain of generations coming and going.

Tornstam [36] further develops thoughts on old age in a life course perspective in his/her theory of gerotranscendence. This means transgressing former capacities and developing new abilities. Some parts of Tornstams [18] description of a development towards gerotranscendence can be recognised in this study. The cosmic dimension, meaning that you see your life as part of a bigger whole, is evident in some interviewees. So is also a reduced focus on oneself (egocentricity), and on material objects. Our informants express movement towards gerotranscendence to varying degrees, but it is not very obvious in the group interviewed. This is also in line with Tornstam's [36] opinion that some develop gerotranscendence to different degrees.

The analysis shows that most of the people interviewed were content with life. They displayed a satisfaction with life were they were mainly doing fine and were generally content. This is in agreement with the understanding of well-being [22] [23]. The theories on well-being seem to better portray the state of mind of the people interviewed than a traditional mental health description of their perception of life. The interviewees showed little to no conventional signs of mental health problems.

Most seemed to do well from the perspective of well-being, although some felt 
lonely at times and with a slightly depressed emotional state. An increasing amount of research centers on what has been named 'the blue zones', aiming at finding determinants for a healthy and long life. So far, nine such determinants have been described [25] [37]. Some of these determinants seem to fit very well together with the sample interviewed in this study, like 1) to move naturally on an everyday basis, 2) feeling a purpose in life (whether it might be for instance a Christian belief or taking part of activities in the senior house), and 3) loved ones first, meaning that the old persons cared for and spent a lot of time in contact with their family and relatives. Other determinants seem to various extents to be in line with what our interviewees said. To combine gerontological (physical and mental) health studies with the growing knowledge on Blue Zones seem to be a promising way of generating knowledge in this field, but also to develop improvements in health and social services, directed to aging populations around the world.

\section{Conclusions}

- People in the "fourth age" interviewed in this study have developed strategies to handle their everyday life and experience well-being.

- The empirical findings generally seem to be in line with the theory of gerotranscendence.

- Urban-rural differences are found to be limited and related to the individual's life stories.

- The elderly that our sample represent is a large and expanding group that still, in high age, lives a mostly independent life, with limited support from family, health and social services, and civil society.

- Terms like the third and the fourth age changes successively as a result of the demographic development and improved mental and physical health among the elderly. This may result in the line between the third and the fourth age being pushed upwards and becoming more dependent on individual factors.

- In this study, the term well-being seem to more relevant than traditional terms and diagnoses to characterise mental health in the elderly.

- The growing knowledge of "blue zones" seems to be a relevant addition with great explanatory value also in research regarding elderly and mental health.

\section{References}

[1] EU (2015) The 2015 Ageing Report. European Economy, 3/2015. Publications Office of the European Union (Online), Luxembourg.

[2] Statistics-Norway (2017) Key Figures for the Population. Statistics Norway, Kongsvinger.

[3] Christensen, K., Doblhammer, G., Rau, R. and Vaupel, J.W. (2009) Ageing Populations: The Challenges Ahead. The Lancet, 374, 1196-1208. https://doi.org/10.1016/S0140-6736(09)61460-4

[4] Adams, K.B., Roberts, A.R. and Cole, M.B. (2011) Changes in Activity and Interest in the Third and Fourth Age: Associations with Health, Functioning and Depressive Symptoms. Occupational Therapy International, 18, 4. 
https://doi.org/10.1002/oti.304

[5] Gynnerstedt, K. and Wolmesjö, M. (2011) Tredje åldern - sociala aspekter och medborgarskap. Gleerups Utbildning AB, Malmø.

[6] Nilsson, B., Lindstrom, U.A. and Naden, D. (2006) Is Loneliness a Psychological Dysfunction? A Literary Study of the Phenomenon of Loneliness. Scandinavian Journal of Caring Sciences, 20, 93-101. https://doi.org/10.1111/j.1471-6712.2006.00386.x

[7] Borglin, G., Edberg, A.-K. and Rahm Hallberg, I. (2005) The Experience of Quality of Life among Older People. Journal of Aging Studies, 19, 201-220. https://doi.org/10.1016/j.jaging.2004.04.001

[8] Tollén, A., Fredriksson, C. and Kamwendo, K. (2008) Elderly Persons with Disabilities in Sweden: Their Experiences of Everyday Life. Occupational Therapy International, 15, 133-149. https://doi.org/10.1002/oti.254

[9] Hedelin, B. and Strandmark, M. (2001) The Meaning of Mental Health from Elderly Women's Perspectives: A Basis for Health Promotion. Perspectives in Psychiatric Care, 37, 7-14. https://doi.org/10.1111/j.1744-6163.2001.tb00611.x

[10] Hedelin, B. and Jonsson, I. (2003) Mutuality as Background Music in Women's Lived Experience of Mental Health and Depression. Journal of Psychiatric and Mental Health Nursing, 10, 317-322. https://doi.org/10.1111/1540-5885.310001-i1

[11] Nilsson, M., Sarvimäki, A. and Ekman, S.L. (2000) Feeling Old: Being in a Phase of Transition in Later Life. Nursing Inquiry, 7, 41-49. https://doi.org/10.1046/j.1440-1800.2000.00049.x

[12] Graneheim, U.H. and Lundman, B. (2010) Experiences of Loneliness among the Very Old: The Umeå 85+ Project. Aging \& Mental Health, 14, 433-438. https://doi.org/10.1080/13607860903586078

[13] Kvaal, K., McDougall, F.A., Brayne, C., Matthews, F.E. and Dewey, M.E. (2008) Co-Occurrence of Anxiety and Depressive Disorders in a Community Sample of Older People: Results from the MRC CFAS (Medical Research Council Cognitive Function and Ageing Study). International Journal of Geriatric Psychiatry, 23, 229-237. https://doi.org/10.1002/gps.1867

[14] McDougall, F.A., Kvaal, K., Matthews, F.E., Paykel, E., Jones, P.B., Dewey, M.E. and Brayne, C. (2007) Prevalence of Depression in Older People in England and Wales: The MRC CFA Study. Psychological Medicine, 37, 1787-1795. https://doi.org/10.1017/s0033291707000372

[15] Atchley, R.C. (1999) Continuity and Adaption in Aging. Creating Positive Experiences. John Hopkins University Press, Baltimore.

[16] Erikson, E.H. (1982) The Life Cycle Completed: A Review. Norton, New York.

[17] Erikson, E.H. and Erikson, J.M. (2004) Den Fullbordade Livscykeln. Natur och kultur, Stockholm.

[18] Tornstam, L. (1999) Transcendence in Later Life. Generations, 23, 10-15.

[19] Tornstam, L. (2011) Åldrandets socialpsykologi. Norsted, Stockholm.

[20] Hauge, S. (1998) An Analysis and Critique of the Theory of Gerotranscendence. Vestfold College, Tønsberg.

[21] Keyes, C. (2006) Subjective Well-Being in Mental Health and Human Development Research Worldwide: An Introduction. Social Indicators Research, 77, 1-10. https://doi.org/10.1007/s11205-005-5550-3

[22] Angner, E. (2012) Fred Feldman, What Is This Thing Called Happiness? (Oxford: Oxford University Press, 2010), pp. xv + 286-ERRATUM. Utilitas, 24, 150. 
https://doi.org/10.1017/S0953820811000446

[23] Soukiazis, E. and Ramos, S. (2016) The Structure of Subjective Well-Being and Its Determinants: A Micro-Data Study for Portugal. Social Indicators Research, 126, 1375-1399. https://doi.org/10.1007/s11205-015-0938-1

[24] Alex Linley, P., Joseph, S., Harrington, S. and Wood, A.M. (2006) Positive Psychology: Past, Present, and (Possible) Future. The Journal of Positive Psychology, 1, 3-16. https://doi.org/10.1080/17439760500372796

[25] Frates, B., Buettner, D. and Skemp, S. (2016) Blue Zones. American Journal of Lifestyle Medicine, 10, 318-321. https://doi.org/10.1177/1559827616637066

[26] Antonovsky, A. (1996) The Salutogenic Model as a Theory to Guide Health Promotion. Health Promotion International, 11, 11-18. https://doi.org/10.1093/heapro/11.1.11

[27] Lindström, B. and Eriksson, M. (2006) Contextualizing Salutogenesis and Antonovsky in Public Health Development. Health Promotion International, 21, 238 244. https://doi.org/10.1093/heapro/dal016

[28] Silverman, D. (2011) Interpreting Qualitative Data. SAGE, Los Angeles.

[29] Kvale, S. and Brinkmann, S. (2009) InterViews: Learning the Craft of Qualitative Research Interviewing. SAGE Publications, Thousand Oaks, CA.

[30] Hummelvoll, J.K. and Barbosa da Silva, A. (1994) A Holistic-Existential Model for Psychiatric Nursing. Perspectives in Psychiatric Care, 30, 7-14. https://doi.org/10.1111/j.1744-6163.1994.tb00229.x

[31] Graneheim, U.H. and Lundman, B. (2004) Qualitative Content Analysis in Nursing Research: Concepts, Procedures and Measures to Achieve Trustworthiness. Nurse Education Today, 24, 105-112. https://doi.org/10.1016/j.nedt.2003.10.001

[32] Schutz, A. (1975) Hverdagslivets Sociologi. Hans Rietzel, Køpenhavn.

[33] Antonovsky, A. (1987) Unraveling the Mystery of Health. How People Manage Stress and Stay Well. Jossey-Brass Publishers, San Francisco.

[34] World Medical Association Declaration of Helsinki (2013) Ethical Principles for Medical Research Involving Human Subjects. JAMA, 310, 2191.

[35] Drageset, I., Normann, K. and Elstad, I. (2012) Familie og kontinuitet; pårørende forteller om livsløpet til personer med demenssykdom. Nordisk Tidsskrift for Helseforskning, 8, 3-19. https://doi.org/10.7557/14.2328

[36] Tornstam, L. (2005) Gerotranscendence: A Developmental Theory of Positive Aging. Springer Publishing Company, New York.

[37] Buettner, D. and Skemp, S. (2016) Blue Zones: Lessons from the World's Longest Lived. American Journal of Lifestyle Medicine, 10, 318-321.

https://doi.org/10.1177/1559827616637066 
Submit or recommend next manuscript to SCIRP and we will provide best service for you:

Accepting pre-submission inquiries through Email, Facebook, LinkedIn, Twitter, etc. A wide selection of journals (inclusive of 9 subjects, more than 200 journals)

Providing 24-hour high-quality service

User-friendly online submission system

Fair and swift peer-review system

Efficient typesetting and proofreading procedure

Display of the result of downloads and visits, as well as the number of cited articles Maximum dissemination of your research work

Submit your manuscript at: http://papersubmission.scirp.org/

Or contact jss@scirp.org 